10 Kamei J, Takahashi Y, Yoshikawa Y, Saitoh A. Involvement of P2X receptor subtypes in ATP-induced enhancement of the cough reflex sensitivity. Eur J Pharmacol 2005; 528: 158-61.

11 Basoglu OK, Pelleg A, Essilfie-Quaye S, Brindicci C, Barnes PJ, Kharitonov SA Effects of aerosolized adenosine 5 '-triphosphate vs adenosine $5^{\prime}$-monophosphate on dyspnea and airway caliber in healthy nonsmokers and patients with asthma. Chest 2005; 128: 1905-09.

12 Ford AP, Undem BJ. The therapeutic promise of ATP antagonism at P2X3 receptors in respiratory and urological disorders. Front Cell Neurosci 2013; 7: 267
13 Lommatzsch M, Cicko S, Müller T, et al. Extracellular adenosine triphosphate and chronic obstructive pulmonary disease. AmJ Respir Crit Care Med 2010; 181: 928-34

14 Khalid S, Murdoch R, Newlands A, et al. Transient receptor potential vanilloid 1 (TRPV1) antagonism in patients with refractory chronic cough: a double-blind randomized controlled trial. J Allergy Clin Immunol 2014; 134: 56-62.e4

\title{
@ 1 oa Care needed in interpretation of cancer survival measures
}

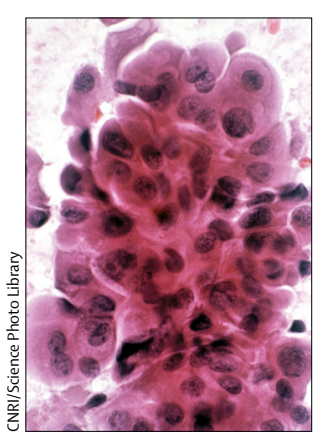

Published Online December 3, 2014 http://dx.doi.org/10.1016/ S0140-6736(14)62292-3 See Articles page 1206

Cancer patient survival obtained from population-based cancer studies is the optimum method to monitor and assess the effectiveness of patient care. ${ }^{1}$ Consideration of these estimates in conjunction with estimates of cancer incidence and mortality is still important. ${ }^{2}$ As a result, there is much interest in the assessment of progress in terms of cancer survival. ${ }^{3,4}$ Quantification of the improvements in cancer patient survival because of successes in some areas, such as treatment, diagnostic techniques, and awareness or screening campaigns, is of paramount importance to health-care officials, health policy makers, and charities supporting these developments in cancer control. However, to make a fair comparison-to compare like with like-is essential to assess progress accurately.

In The Lancet, Manuela Quaresma and colleagues ${ }^{5}$ report the creation of a survival index that is useful to compare improvements in cancer patient survival over time. The authors show that the index of net survival increased substantially in cancer patients in England and Wales over the period 1971-2011. To make comparisons across time for all cancer sites combined is difficult because of changing age distributions for patients with cancer alongside a changing distribution of sites. For instance, if less fatal cancers become relatively more common, an improvement would be

\begin{tabular}{|lllll|}
\hline & $\begin{array}{l}\text { 10-year net } \\
\text { probability of death } \\
\text { (1-relative survival) }\end{array}$ & $\begin{array}{l}\text { 10-year crude (actual) } \\
\text { probability of death } \\
\text { due to cancer }\end{array}$ & $\begin{array}{l}\text { 10-year crude (actual) } \\
\text { probability of death } \\
\text { due to other causes }\end{array}$ & $\begin{array}{l}\text { 10-year crude (actual) } \\
\text { probability of death } \\
\text { due to any cause }\end{array}$ \\
\hline 40 years & 0.50 & 0.49 & 0.02 & 0.51 \\
60 years & 0.50 & 0.48 & 0.08 & 0.57 \\
80 years & 0.50 & 0.42 & 0.42 & 0.84 \\
\hline
\end{tabular}

Derived from an England and Wales life table. Columns 2 and 3 give the actual probabilities of death due to the disease and due to other causes, and sum to the value given in column 4 (the overall probability of death). The first column gives a net measure and has no interpretation as the actual probability of death due to cancer.

Table: Synthetic example of survival by patient age in which 10 -year net survival is $50 \%$ for all ages seen in all-cancer survival, but not necessarily because of any improvements for any individual cancer site. One further issue with comparisons of survival after cancer is that the chance of dying from another cause also changes over time. Quaresma and colleagues 5 overcome these difficulties by defining a survival index that estimates average relative survival in different time periods, but the index is standardised to the distribution of both age and cancer site in 1996-99. Relative survival compares the survival in patients with cancer to a relevant cohort without cancer, and is important to account for the changing risk of dying of something else. Under specific assumptions, ${ }^{6}$ average relative survival estimates marginal net survival, which is completely independent of other-cause mortality. The standardisation to 1996-99 neatly overcomes the other issues of comparability (age and cancer distributions), but comes at the cost of the inability to interpret the measures. Measures that are optimum for comparability cannot be easily interpreted in terms of the survival experience of individuals, and vice versa.

The authors note that the figures they report are readily interpreted incorrectly. ${ }^{7,8}$ The survival index for all cancers combined is something of a holy grail for headline writers, because it gives one summary figure to show progress in cancer as a whole over time. However, similarly to all averages and summaries, important detail lies behind the number. The survival index (and the site-specific estimates) measure net survival, which adds substantially to the difficulty in interpretation, but that subtlety is often missed. The all-cancer survival index of $50 \%$ at 10 years might be interpreted as meaning that $50 \%$ of cancer patients will survive for 10 years or more, which is wrongas the authors discuss $5^{5}$-but it is worth stressing this point. The problem relates to the three main 
adjustments necessary for making the index possible to compare across time. The measure is independent of competing mortality because of other causes that also heavily affect patients with cancer; for most sites, the diagnosed patients are of an older age.

I show an example in which the relative survival estimate at 10 years is $50 \%$ at every age. England and Wales population mortality data are used to convert these estimates ${ }^{9,10}$ into the 10 year all-cause probability of death (table). An 80 -year-old has a $16 \%$ chance of being alive at 10 years, despite the net estimate of $50 \%$. For younger patients, the differences are smaller, but still exist. Overall, fewer patients with cancer will be alive 10 years after diagnosis if we use all-cause death as the outcome, rather than a net measure. Difficulties are also introduced by standardisation; patients with cancer diagnosed now (and in the future) might be older on average, and have a higher proportion of cancers with a better or worse prognosis than in 1996-99. The survival index is being standardised to a population that might not be a good representation of the present population structure, making present and future interpretability of the measure more difficult. Additionally, any biases in site-specific estimates will also contribute to the survival index.

Quaresma and colleagues mainly concentrate on age-standardised measures. However, the age-group specific estimates need to be examined across each site to understand fully whether improvements in outcomes occur across all ages simultaneously, which is unlikely to be the case. For instance, certain treatment improvements will be seen only for younger patients. Although the overall measures reported as headline figures are important, understanding of the reasons for the changes over time is even more important. Quaresma and colleagues fit very sophisticated models to arrive at the values that they present. A lot of extra information can be garnered from these models. Metrics that underline in which subgroups of patients and at what point in follow-up improvements have occurred should be further used. ${ }^{11,12}$

Overall, Quaresma and colleagues should be congratulated on a carefully constructed method for comparisons across time. This is a useful epidemiological measure for quantification of overall improvements in cancer survival. The site-specific indices are particularly useful to understand whether progress has been made and when in calendar time we observe the improvement. However, caution should be used when interpreting the figures themselves. I would encourage the continued development of statistical approaches that help to pinpoint the reasons for these overall improvements. I would also further stress that other statistical metrics, which are more readily interpretable for patients and health-care professionals, should be used. ${ }^{12}$

\section{MarkJ Rutherford}

Department of Health Sciences, University of Leicester, University Road, Leicester LE1 7RH, UK

mark.rutherford@le.ac.uk

I declare no competing interests.

Copyright @ Rutherford et al. Open Access article distributed under the terms of CCBY.

1 Dickman PW, Adami HO. Interpreting trends in cancer patient survival. J Intern Med 2006; 260: 103-17.

2 Ellis L, Woods LM, Estève J, Eloranta S, Coleman MP, Rachet B. Cancer incidence, survival and mortality: explaining the concepts. Int J Cancer 2014; 135: 1774-82.

3 Coleman M, Forman D, Bryant $\mathrm{H}$, et al. Cancer survival in Australia, Canada, Denmark, Norway, Sweden, and the UK, 1995-2007 (the International Cancer Benchmarking Partnership): an analysis of population-based cancer registry data. Lancet 2011; 277: 127-38.

4 De Angelis R, Sant M, Coleman MP, et al, and the EUROCARE-5 Working Group. Cancer survival in Europe 1999-2007 by country and age: results of EUROCARE-5-a population-based study. Lancet Oncol 2014; 15: 23-34.

5 Quaresma M, Coleman MP, Rachet B. 40-year trends in an index of survival for all cancers combined and survival adjusted for age and sex for cancers in England and Wales, 1971-2011: a population-based study. Lancet 2014; published online Dec 3. http://dx.doi.org/10.1016/S0140-6736(14)61396-9.

6 Perme MP, Stare J, Estève J. On estimation in relative survival. Biometrics 2012; 68: 113-20

7 Borland S. Half of cancer patients are living for ten years or more: number classed as having beaten the disease doubles since the 1970s. 2014. http://www.dailymail.co.uk/health/article-2615416/half-cancer-patientsliving-ten-years-number-classed-having-beaten-disease-doubles-1970s (accessed Aug 27, 2014).

8 Boseley S. Cancer survival rates: half of new UK patients 'can expect to live for another decade'. April 29, 2014. http://www.theguardian.com/society/2014/ apr/29/cancer-patients-uk-survival-rates (accessed Aug 27, 2014).

9 Cronin KA, Feuer EJ. Cumulative cause-specific mortality for cancer patients in the presence of other causes: a crude analogue of relative survival. Stat Med 2000; 19: 1729-40.

10 Lambert PC, Dickman PW, Nelson CP, Royston P. Estimating the crude probability of death due to cancer and other causes using relative survival models. Stat Med 2010; 29: 885-95.

11 Lambert PC, Holmberg L, Sandin F, et al. Quantifying differences in breast cancer survival between England and Norway. Cancer Epidemiol 2011; 35: 526-33.

12 Eloranta, Adolfsson J, Lambert PC, et al. How can we make cancer survival statistics more useful for patients and clinicians: an illustration using localized prostate cancer in Sweden. Cancer Causes Control 2013; 24: 505-15. 